\title{
The Rehabilitative Effects of Virtual Reality Games on Balance Performance among Children with Cerebral Palsy: A Meta-Analysis of Randomized Controlled Trials
}

\author{
Jinlong $\mathrm{Wu}^{1}$, Paul D. Loprinzi ${ }^{2} \mathbb{C}$ and Zhanbing Ren ${ }^{1, *}$ \\ 1 Department of Physical Education, Shenzhen University, Shenzhen 518061, China; \\ 1800371011@email.szu.edu.cn \\ 2 Department of Health, Exercise Science and Recreation Management, University of Mississippi, \\ Oxford, MS 38655, USA; pdloprin@olemiss.edu \\ * Correspondence: rzb@szu.edu.cn
}

Received: 30 August 2019; Accepted: 25 October 2019; Published: 28 October 2019

\begin{abstract}
This research aims to evaluate the effect of virtual reality (VR) games on balance recovery of children with cerebral palsy $(\mathrm{CP})$ by quantitatively synthesizing the existing literature, and to further determine the impact of VR game intervention (the duration of each intervention, intervention frequency, intervention cycle, and total intervention time) on the balance recovery of children with $\mathrm{CP}$. To this end, relevant literature up until 3 August 2019 was retrieved from Chinese databases (CNKI and Wanfang Data) and the databases in other languages (Web of Science, Pubmed, EBSCOhost, Informit, Scopus, Science Direct, and ProQuest), and bias analysis was conducted with the PEDro scale in this research. Randomized controlled trials (RCTs) were selected and underwent meta-analysis, and combined effect size was calculated with a random effects model. The results showed that VR games may improve the balance of children with CP (Hedge's $g=0.29 ; 95 \%$ CI $0.10-0.48$ ), and no significant influence of the intervention on balance of children with $\mathrm{CP}$ was shown in the subgroup analysis. In conclusion, VR games played a positive role in the improvement of balance of children with $\mathrm{CP}$, but these results should be viewed with caution owing to current methodological defects (difference in measurement, heterogeneity of control groups, intervention combined with other treatments, etc.).
\end{abstract}

Keywords: virtual reality games; balance; cerebral palsy

\section{Introduction}

Cerebral palsy (CP) is a type of neurodevelopmental disorder that appears during infancy or early childhood, caused by brain injury or developmental defects [1]. According to the World Health Organization, the incidence of $\mathrm{CP}$ in developed countries ranges from $0.2 \%$ to $0.3 \%$, making it a major problem for public health [2]. Damage to the central nervous system may cause secondary injuries to children with $\mathrm{CP}$, including physical spasm, amyotrophy/weak muscle tone, skeletal deformity, myasthenia, and developmental coordination disorder [3,4], which results in balance dysfunction. Consequently, the $\mathrm{CP}$ children who have balance impairment are more likely to experience increasing numbers of falls and develop more limited motor skills [5]. Well-established balance ability is a fundamental element helping individuals to learn and acquire a different level of motor skills [6]. Furthermore, it is important for children with $\mathrm{CP}$ to live an everyday life and take part in social activities and entertainment [6]. Thus, balance function is deemed as an important indicator for the assessment of motor skills of children with CP [7]. 
Maintaining one's balance requires continuous and simultaneous data processing from multiple systems (e.g., vestibular, visual, proprioception, and cognitive reintegration) [8,9]. When these systems have been impacted by a neurological injury, balance and balance-contingent activities are affected [10]. Virtual reality (VR) games are whole-body interactive electronic games that feature a three-dimensional display and body perception operated by body movements [11]. These virtual reality games typically use sensory-motor experiences including sight, sound, and touch to simulate environments and activities. Computer screens with special displays are used to present visual imagery while headphones or speakers deliver sound. These immersive virtual environments can be used in balance training by providing continuous visual information to the user that can be used as sensory feedback by the vestibular system to create successful movements. Additionally, the use of virtual avatars performing the same balance training on screen provides users the ability to mirror and modulate their movements in real-time [10]. For children with $\mathrm{CP}$ whose cognitive abilities are still in development, however, VR games can engage them and help them carry out repetitive rehabilitation exercises [12]. By the virtue of real-time feedback on human, vision, and feeling from the virtual environment created by VR games, children with CP can interact with the VR environment, and the duration of activities, the intensity of exercises, and times of repetition can be increased [13-15].

Current rehabilitation for children with $\mathrm{CP}$ focuses on regular rehabilitation training (mainly Bobath and Rood therapeutic methods). However, compared to traditional treatment options, Virtual reality games are a kind of whole-body interactive video game where people can physically immerse in a non-physical world through a three-dimensional display at home [16]. Such an immersive experience in a safe, enjoyable, and playful environment is associated with less fatigue and more relaxation, which may be beneficial for children, including those with CP [17]. Published studies have evaluated the effect of VR games on the upper limb motor skills of children with CP and demonstrated that VR games can improve the upper limb motor skills in this population [18]. Further, a systematic review showed that VR games can enhance the gross motor skills of children with CP, but, notably, these studies lacked a randomized controlled design. A recent systematic review evaluating the balance ability of children with $\mathrm{CP}$ found that VR games can, potentially, improve the postural control and balance ability of children with CP [19]. Nevertheless, the evidence of VR games as a therapeutic intervention in children with $\mathrm{CP}$ is insufficient, failing to quantitatively reflect these games' effectiveness of intervening in the development of balance ability of children with CP. Since there is scant attention paid to the balance of children with $\mathrm{CP}$, the main purpose of this research is to explore the effect of VR games on the enhancement of the balance of children with $\mathrm{CP}$, and to further determine the influence of VR games intervention (session length, intervention frequency, intervention cycle, and total intervention time) over the balance of children with $\mathrm{CP}$, so as to lay an important theoretical groundwork for the effect of therapeutic intervention in the balance development of children with $\mathrm{CP}$.

\section{Methods}

This research follows the instructions of the preferred reporting items for systematic review and meta-analysis (PRISMA) statement [20,21].

\subsection{Retrieval Strategy}

The literature in Chinese databases (CNKI and Wanfang Data) and the databases in foreign languages (Web of Science, PubMed, EBSCOhost, Informit, Scopus, Science Direct, and ProQuest) as of 3 August 2019 was retrieved, with "active video game", "VR game, "video game, " children with CP" and "children with cerebral palsy" as Chinese keywords, and "exergame", "AVG", "active video game", "active video gaming", "Wii", "Play Station", "Kinect", "virtual reality", "cerebral palsy", "cerebral palsies", "Little disease", "infantile palsies", "spastic diplegia", "spastic diplegias", "spastic diplegic", "spastic hemiplegia", "spastic hemiplegias", "spastic hemiplegic", "spastic quadriplegia", "spastic quadriplegias", "spastic quadriplegic", "postural control", "trunk control", "posture", and "balance" as English keywords. 


\subsection{Inclusion Criteria}

The included studies contain Randomized controlled trials (RCTs), and they were included as per the criteria within the Patient Intervention Control Outcome Setting Time (PICOST) framework [22]. Studies were considered eligible if they met the following inclusion criteria. Firstly, studies with a randomized controlled design needed to be published in a peer-reviewed journal. Secondly, study participants were who were at the age of 14 or below and had been diagnosed with CP. Thirdly, virtual reality games were used as the main intervention program to compare non-active and/or active control condition (s). Fourth, balance performance was measured using a valid instrument (the Movement Assessment Battery for Children, the Pediatric Balance Scale, and the Timed Up and Go test). Lastly, useful data (e.g., sample size, mean, and standard deviation) were clearly reported in the published paper or can be retrieved through contacting corresponding author of primary studies. Two researchers independently screened and determined the eligibility of initially retrieved studies against the aforementioned inclusion criteria $[23,24]$. Notably, the title/abstract was screened, with eligibility agreement that had reached at least $93.5 \%$.Afterwards, Full-text of the remaining items were assessed according to the inclusion criteria, with agreement of $100 \%$.

\subsection{Quality Assessment}

The Kappa index is often used to analyze the consistency of two people's (or two test methods') opinions on the same subject. The standard of general judgment is: Kappa index $>0.75$ indicates better consistency, $0.75 \leq$ Kappa index $\leq 0.4$ indicates good consistency, and Kappa index $<0.4$ indicates poor consistency. The risk of bias of the included studies was carried out by two independent researchers as per the PEDro scale [25-27]. In case of divergence of opinion between the two assessors, a third assessor was consulted. The following 11 criteria were taken into consideration (one point for each criterion): (a) eligibility criteria were specified; (b) subjects were randomly allocated to groups; (c) allocation was concealed; (d) the groups were similar at baseline regarding the most important outcome indicators; (e) there was blinding of all subjects; (f) there was blinding of all therapists; (g) there was blinding of all assessors; (h) measures of at least one key outcome were obtained from more than $85 \%$ of the subjects initially allocated to groups; (i) all subjects for whom outcome measures were available received the treatment or, where this was not the case, data for at least one key outcome was analyzed by "intention to treat"; (j) the results of between-group statistical comparisons were reported for at least one key outcome; (k) the study provided both point measures and measures of variability for at least one key outcome. The highest mark for each study was 11: low risk of bias ( $\geq 7$ or more); moderate risk of bias (5-6); high risk of bias ( $\leq 4$ or less).

\subsection{Data Extraction}

In the process of retrieval, two researchers independently extracted both descriptive and quantitative data of each included study, and the data were placed in the pre-designed extraction Excel spreadsheet in this order: first author name(s), the year of publication, country, subjects (number, genders, ages), intervention scheme (location(s), method(s), frequency of VR game intervention, time of the intervention), VR game platform(s), VR game type(s), and outcome indicators. Further, the baselines of eligible RCTs and control groups as well as the means (M) and standard deviations (SD) after interventions were also extracted.

\subsection{Data Analysis}

The software Review Manager 5.3 was used in the analysis of outcome indicators of the 11 included studies. Hedge's g was used to calculate the effect size of each experiment, and the standardized mean difference (SMD) was selected to calculate the effect scale indicators. The effect size shows the influence of VR games on the balance of children with $\mathrm{CP}$, which was calculated through a random effects model and for which $95 \%$ CI was applied [28]. The $I^{2}$ statistic was used to perform the heterogeneity test: 
when $I^{2} \leq 50 \%$, it indicates no heterogeneity in the studies; when $I^{2}>50 \%$, it suggests heterogeneity in the studies, in which case, sensitivity analysis would be conducted to determine the sources of heterogeneity by deleting one study each time. As for subgroup analysis of moderators, intervention schemes were categorized depending on: Session length ( 15 to $40 \mathrm{~min}, \geq 40 \mathrm{~min}$ ), intervention frequency ( 2 to 5 sessions/weekly, $\geq 5$ sessions/weekly), intervention cycle ( 3 to 12 weeks, $\geq 12$ weeks) and total intervention time (480 to $1000 \mathrm{~min}, \geq 1000 \mathrm{~min}$ ). Additionally, the funnel plot and Egger's test were used to assess publication bias [29].

\section{Results}

\subsection{Retrieval Results}

A total of 473 relevant studies were found through article retrieval, including 65 from PubMed, 66 from EBSCOhost, 101 from Web of Science, 52 from InFormit, 34 from Scopus, 96 from Science Direct, and 38 from ProQuest. As for Chinese databases, 9 relevant studies were found through CNKI and 6 found through Wanfang Data. The overall number was reduced to 367 after repeated studies were deleted through NoteExpress 3.2.0. Considering their titles and abstracts, 15 studies were selected, and given the full text of these 15 studies, 4 were excluded due to their failure to meet the inclusion criteria. As a result, 11 RCTs were included in this research (Figure 1).

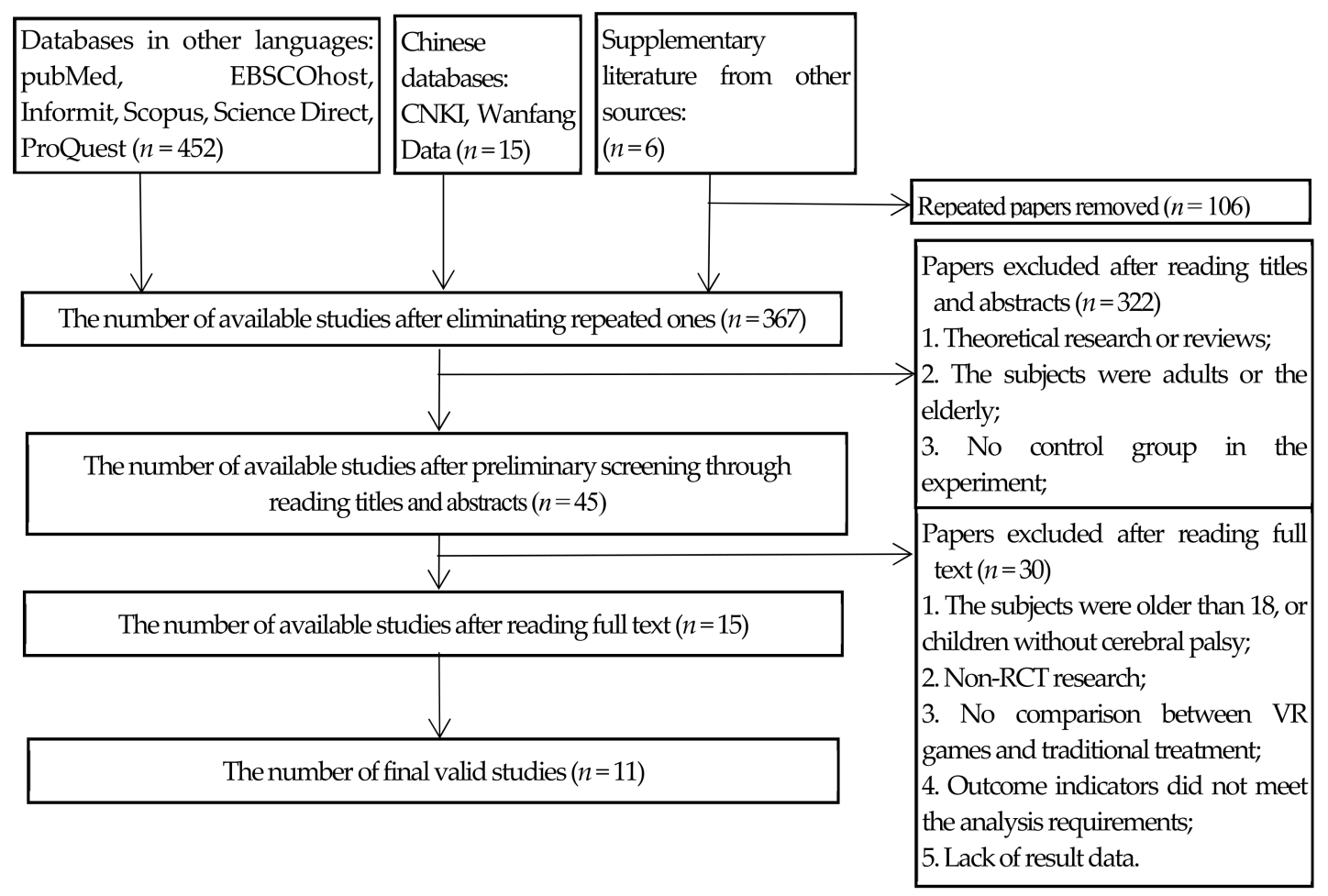

Figure 1. The flow chart of literature screening.

\subsection{Study Characteristics}

The characteristics of 11 included studies are listed in Table 1. These studies were published from 2010 to 2019, with 7 in English [14,30-35], 3 in Chinese [36-38] and 1 in Korean [39]. Despite the fact that all subjects were children with $\mathrm{CP}$, there were differences among them (children with paralytic hemiplegia, children with postoperative cerebral palsy, children with hemiplegic cerebral palsy, children with spastic diplegia, children with spastic hemiplegia, and children with spastic quadriplegia). The sample size of each study ranged from 16 to 48 subjects, with a total number of 313 . Most of the studies reported the GMFCS levels, genders, and intervention locations of children with 
CP, whereas two studies did not report the GMFCS levels [32,34], two did not report the genders of subjects [32,33], and two did not report intervention locations [32,34]. The content of intervention was the comparison between VR game schemes and regular rehabilitation schemes as well as the comparison between VR game plus regular rehabilitation schemes and regular rehabilitation schemes. Firstly, the session length from 15 to $40 \mathrm{~min}$ (in one of the studies, the duration of each intervention depended on the duration of time). Secondly, intervention frequency was between twice and seven times, with the total intervention time ranging from 480 to $2400 \mathrm{~min}$. Thirdly, intervention cycles also showed large differences, with the minimum cycle being as short as 4 weeks and the maximum reaching 12 weeks.

There were differences in the intervention platforms. Most interventions chose Nintendo as the platform, and the others included the Q4 situational interactive rehabilitation training system, the Xbox Kinect platform, the Biomaster VR training system, and the Scratch software. Compared with intervention groups, control groups included strength training and neurodevelopmental therapy apart from regular rehabilitation. On top of that, in the 11 studies, 8 had only one outcome indicator of balance, and the other $3[14,30,34]$ had two outcome indicators of balance. 
Table 1. List of basic characteristics of the included studies.

\begin{tabular}{|c|c|c|c|c|c|c|c|c|c|c|}
\hline \multirow{2}{*}{ Researchers } & \multirow{2}{*}{ Subjects } & \multirow{2}{*}{$\begin{array}{l}\text { Country: } \\
\text { Language }\end{array}$} & \multicolumn{2}{|c|}{ GMFCS Level (Number) } & \multirow{2}{*}{$\begin{array}{l}\text { Characteristics of Subjects } \\
\text { (Number; Genders; Ages) }\end{array}$} & \multirow{2}{*}{$\begin{array}{l}\text { Intervention Methods; } \\
\text { Frequency of the Intervention } \\
\text { Group; Total Time of the } \\
\text { Intervention Group }\end{array}$} & \multirow{2}{*}{$\begin{array}{l}\text { Intervention } \\
\text { Location }\end{array}$} & \multirow{2}{*}{ VR Platforms } & \multirow{2}{*}{$\begin{array}{l}\text { Types of VR } \\
\text { Game }\end{array}$} & \multirow{2}{*}{$\begin{array}{l}\text { Outcome } \\
\text { Indicators }\end{array}$} \\
\hline & & & $\begin{array}{l}\text { Experimental } \\
\text { Group }\end{array}$ & $\begin{array}{l}\text { Control } \\
\text { Group }\end{array}$ & & & & & & \\
\hline $\begin{array}{l}\text { Han et al. [39] } \\
\text { (2010) }\end{array}$ & $\begin{array}{l}\text { Children with } \\
\text { paralytic } \\
\text { hemiplegia }\end{array}$ & $\begin{array}{l}\text { South Korea: } \\
\text { Korean }\end{array}$ & $\begin{array}{l}\mathrm{L}(1): 9 \\
\mathrm{~L}(2): 1\end{array}$ & $\begin{array}{l}\mathrm{L}(1): 8 \\
\mathrm{~L}(2): 2\end{array}$ & $\begin{array}{l}\text { 20; the experimental group: } 10 \text { : } \\
5 \text { males }(9.50 \pm 2.46) ; \text { the } \\
\text { control group: } 10: 5 \text { males } \\
(8.90 \pm 2.37)\end{array}$ & $\begin{array}{c}\text { Strength training treatment + } \\
\text { VRGs treatment; } 15 \mathrm{~min} / \mathrm{time,} 3 \\
\text { days/week, } 12 \text { weeks in total; } \\
540 \mathrm{~min}\end{array}$ & Hospital & $\begin{array}{l}\text { Nintendo wii fit } \\
\text { balance board }\end{array}$ & $\begin{array}{l}\text { Warrior posture; } \\
\text { wire-waling; } \\
\text { rafting in the } \\
\text { valley }\end{array}$ & (2) \\
\hline $\begin{array}{l}\text { Sharan et al. [32] } \\
\text { (2012) }\end{array}$ & $\begin{array}{l}\text { Children with } \\
\text { postoperative } \\
\text { cerebral palsy }\end{array}$ & $\begin{array}{l}\text { India: } \\
\text { English }\end{array}$ & Not Clear & Not Clear & $\begin{array}{c}\text { 16; the experimental group: } 8 \\
(8.88 \pm 3.23) \text {; the control group: } \\
8(10.38 \pm 4.41) \text { (NSL) }\end{array}$ & $\begin{array}{l}\text { Depending on game types, } 3 \\
\text { days/time, } 3 \text { weeks in total }\end{array}$ & Not clear & Nintendo wii-fit & $\begin{array}{c}\text { Depending on } \\
\text { children's abilities }\end{array}$ & (2) \\
\hline $\begin{array}{l}\text { Alsaif and } \\
\text { Alsenany [33] } \\
\text { (2015) }\end{array}$ & $\begin{array}{l}\text { Children with } \\
\text { spastic diplegia }\end{array}$ & $\begin{array}{l}\text { Saudi } \\
\text { Arabia: } \\
\text { English }\end{array}$ & $\mathrm{L}(3): 20$ & L(3):20 & $\begin{array}{l}\text { 40; the experimental group: 20; } \\
\text { the control group: 20; } \\
\text { 6-to-10-year-olds (NSL) }\end{array}$ & $\begin{array}{c}\text { VRGs; } 20 \mathrm{~min} / \text { day, } 7 \\
\text { times/week, } 12 \text { weeks in total; } \\
1680 \mathrm{~min}\end{array}$ & Home & $\begin{array}{l}\text { Nintendo wii fit } \\
\text { balance board }\end{array}$ & Not specified & (1) \\
\hline $\begin{array}{l}\text { Atasavun et al. } \\
\text { [31] (2016) }\end{array}$ & $\begin{array}{l}\text { Children with } \\
\text { hemiplegic } \\
\text { cerebral palsy }\end{array}$ & $\begin{array}{l}\text { Turkey: } \\
\text { English }\end{array}$ & $\begin{array}{l}\mathrm{L}(1): 9 \\
\mathrm{~L}(2): 3\end{array}$ & $\begin{array}{l}\mathrm{L}(1): 10 \\
\mathrm{~L}(2): 2\end{array}$ & $\begin{array}{l}\text { 24; the experimental group: } 12 \text { : } \\
8 \text { males; the control group: 12: } \\
2 \text { males; } 6 \text {-to-14-year-olds }\end{array}$ & $\begin{array}{c}\text { Regular rehabilitation } \\
\text { treatment + VRGs treatment; } \\
30 \mathrm{~min} / \mathrm{time}, 2 \text { days/week, } 12 \\
\text { weeks in totali; } 720 \mathrm{~min}\end{array}$ & Hospital & Nintendo wii-fit & $\begin{array}{c}\text { Wii basketball } \\
\text { game; Wii football } \\
\text { game; Wii boxing } \\
\text { game }\end{array}$ & (2) \\
\hline $\begin{array}{l}\text { Trakci et al. [14] } \\
\text { (2016) }\end{array}$ & $\begin{array}{l}\text { Children with } \\
\text { hemiplegic } \\
\text { cerebral palsy }\end{array}$ & $\begin{array}{l}\text { Turkey: } \\
\text { English }\end{array}$ & $\mathrm{L}(1 \sim 2): 15$ & $\mathrm{~L}(1 \sim 3): 15$ & $\begin{array}{l}\text { 30; the experimental group: } 15: \\
10 \text { males }(10.46 \pm 2.69) \text {; the } \\
\text { control group: } 15: 9 \text { males } \\
(10.53 \pm 2.79)\end{array}$ & $\begin{array}{l}\text { Neurodevelopmental therapy + } \\
\text { VRGs treatment; } 20 \text { min/time, } \\
\text { twice per week, } 12 \text { weeks in } \\
\text { total; } 480 \text { min }\end{array}$ & $\begin{array}{l}\text { Rehabilitation } \\
\text { Centre }\end{array}$ & Nintendo wii-fit & $\begin{array}{l}\text { Slalom; } \\
\text { wire-walking; } \\
\text { football game }\end{array}$ & (3)(5) \\
\hline $\begin{array}{l}\text { Ren et al. [37] } \\
\quad(2016)\end{array}$ & $\begin{array}{l}\text { Children with } \\
\text { spastic diplegia }\end{array}$ & $\begin{array}{l}\text { China: } \\
\text { Chinese }\end{array}$ & $\begin{array}{l}\mathrm{L}(1): 8 \\
\mathrm{~L}(2): 11\end{array}$ & $\begin{array}{l}\mathrm{L}(1): 7 \\
\mathrm{~L}(2): 9\end{array}$ & $\begin{array}{l}\text { 35; the experimental group: } 19 \text { : } \\
11 \text { males and } 8 \text { females } \\
\text { (53.88 } \pm 13.58) \text {; the control } \\
\text { group: } 16: 9(56.53 \pm 9.67)\end{array}$ & $\begin{array}{l}\text { Regular rehabilitation } \\
\text { treatment + VRGs treatment; } \\
40 \text { min/time, } 5 \text { times/week, } 12 \\
\text { weeks in total; } 2400 \text { min }\end{array}$ & Hospital & $\begin{array}{l}\text { Q4 situational } \\
\text { interactive } \\
\text { rehabilitation } \\
\text { training system } \\
\text { produced by } \\
\text { OPEM }\end{array}$ & Not specified & (4) \\
\hline $\begin{array}{l}\text { Rgen et al. [34] } \\
\text { (2016) }\end{array}$ & $\begin{array}{c}\text { Children with } \\
\text { spastic hemiplegia }\end{array}$ & $\begin{array}{l}\text { Turkey: } \\
\text { English }\end{array}$ & Not Clear & Not Clear & $\begin{array}{l}\text { 30; the experimental group: } 15 \text { : } \\
7 \text { males (11.07 } \pm 2.37) \text {; the } \\
\text { control group: } 15: 7 \text { males } \\
\text { (11.33 } \pm 2.19)\end{array}$ & $\begin{array}{l}\text { Regular rehabilitation } \\
\text { treatment + VRGs treatment; } \\
40 \text { min/time, twice per week, } 9 \\
\text { weeks in total; } 720 \text { min }\end{array}$ & Not Clear & Nintendo wii-fit & $\begin{array}{c}\text { Ski jumping; } \\
\text { snowball fight; } \\
\text { jogging; the } \\
\text { oblique city; } \\
\text { penguin slides; } \\
\text { perfect 10; } \\
\text { guiseway; header }\end{array}$ & (5)(6) \\
\hline $\begin{array}{l}\text { Sajan et al. [35] } \\
\text { (2017) }\end{array}$ & $\begin{array}{l}\text { Children with } \\
\text { double lower limb } \\
\text { paralytic and } \\
\text { quadriplegic } \\
\text { cerebral palsy } \\
\end{array}$ & $\begin{array}{l}\text { India: } \\
\text { English }\end{array}$ & $\begin{array}{l}\mathrm{L}(1): 1 \\
\mathrm{~L}(2): 2 \\
\mathrm{~L}(3): 6 \\
\mathrm{~L}(4): 1\end{array}$ & $\begin{array}{l}\mathrm{L}(2): 1 \\
\mathrm{~L}(3): 7 \\
\mathrm{~L}(4): 2\end{array}$ & $\begin{array}{l}\text { 20; the experimental group: } 10 \text { : } \\
5 \text { males (12.4 } \pm 4.93) ; \text { the } \\
\text { control group: } 10: 6 \text { males } \\
\text { (10.6 } \pm 3.78)\end{array}$ & $\begin{array}{c}\text { Regular rehabilitation + VRGs } \\
\text { treatment; } 30 \mathrm{~min} / \text { time, } 6 \\
\text { times/week, } 3 \text { weeks in total; } \\
540 \mathrm{~min}\end{array}$ & Clinical & $\begin{array}{l}\text { Nintendo Wii-fit } \\
\text { remote control } \\
\text { game }\end{array}$ & Boxing; tennis & (2) \\
\hline $\begin{array}{l}\text { Zhao et al. [36] } \\
\text { (2018) }\end{array}$ & $\begin{array}{l}\text { Children with } \\
\text { hemiplegic, } \\
\text { diplegic and } \\
\text { quadriplegic } \\
\text { cerebral palsy }\end{array}$ & $\begin{array}{l}\text { China: } \\
\text { Chinese }\end{array}$ & $\begin{array}{l}\mathrm{L}(1): 18 \\
\mathrm{~L}(2): 6\end{array}$ & $\begin{array}{l}\mathrm{L}(1): 17 \\
\mathrm{~L}(2): 7\end{array}$ & $\begin{array}{l}\text { 48; the experimental group: } 24 \text { : } \\
11 \text { males (59.38 } \pm 11.29) \text {; the } \\
\text { control group: } 24: 16 \text { males } \\
(54.33 \pm 10.93)\end{array}$ & $\begin{array}{l}\text { Regular rehabilitation } \\
\text { treatment + VRGs treatment; } \\
40 \mathrm{~min} / \text { time, } 5 \text { times/week,3 } \\
\text { weeks in total; } 600 \mathrm{~min}\end{array}$ & Hospital & $\begin{array}{l}\text { Active video } \\
\text { games on the } \\
\text { Xbox Kinect } \\
\text { platform }\end{array}$ & Dance Imitation & (2) \\
\hline
\end{tabular}


Table 1. Cont.

\begin{tabular}{|c|c|c|c|c|c|c|c|c|c|c|}
\hline \multirow{2}{*}{ Researchers } & \multirow{2}{*}{ Subjects } & \multirow{2}{*}{$\begin{array}{l}\text { Country: } \\
\text { Language }\end{array}$} & \multicolumn{2}{|c|}{ GMFCS Level (Number) } & \multirow{2}{*}{$\begin{array}{l}\text { Characteristics of Subjects } \\
\text { (Number; Genders; Ages) }\end{array}$} & \multirow{2}{*}{$\begin{array}{l}\text { Intervention Methods; } \\
\text { Frequency of the Intervention } \\
\text { Group; Total Time of the } \\
\text { Intervention Group }\end{array}$} & \multirow{2}{*}{$\begin{array}{l}\text { Intervention } \\
\text { Location }\end{array}$} & \multirow{2}{*}{ VR Platforms } & \multirow{2}{*}{$\begin{array}{l}\text { Types of VR } \\
\text { Game }\end{array}$} & \multirow{2}{*}{$\begin{array}{l}\text { Outcome } \\
\text { Indicators }\end{array}$} \\
\hline & & & $\begin{array}{l}\text { Experimental } \\
\text { Group }\end{array}$ & $\begin{array}{l}\text { Control } \\
\text { Group }\end{array}$ & & & & & & \\
\hline $\begin{array}{l}\text { Hsieh et al. [40] } \\
\quad \text { (2018) }\end{array}$ & $\begin{array}{l}\text { Children with } \\
\text { diplegic and } \\
\text { quadriplegic } \\
\text { cerebral palsy }\end{array}$ & $\begin{array}{l}\text { Taiwan, } \\
\text { China: } \\
\text { English }\end{array}$ & $\begin{array}{l}\mathrm{L}(2): 10 \\
\mathrm{~L}(3): 6 \\
\mathrm{~L}(4): 4\end{array}$ & $\begin{array}{l}\mathrm{L}(2): 10 \\
\mathrm{~L}(3): 5 \\
\mathrm{~L}(4): 5\end{array}$ & $\begin{array}{l}40 \text {; the experimental group: } 20 \text { : } \\
14 \text { males }(7.33 \pm 1.31) \text {; the } \\
\text { control group: } 15: 12 \text { males } \\
\text { (7.41 } \pm 1.54)\end{array}$ & $\begin{array}{l}\text { Regular rehabilitation } \\
\text { treatment + VRGs treatment; } \\
40 \mathrm{~min} / \text { time, } 5 \text { times/week,12 } \\
\text { weeks in total; } 2400 \mathrm{~min}\end{array}$ & Not Clear & $\begin{array}{l}\text { computer }+ \\
\text { joystick (the } \\
\text { software } \\
\text { Scratch) }\end{array}$ & $\begin{array}{c}\text { Flower watering, } \\
\text { monkey eating } \\
\text { bananas, killing } \\
\text { mosquitoes with a } \\
\text { swatter } \\
\end{array}$ & (3)(5) \\
\hline $\begin{array}{l}\text { Yang et al. [38] } \\
\text { (2019) }\end{array}$ & $\begin{array}{l}\text { Children with } \\
\text { spastic diplegia }\end{array}$ & $\begin{array}{l}\text { China: } \\
\text { Chinese }\end{array}$ & L(3):20 & L(3):20 & $\begin{array}{l}45 \text {; the experimental group: } 23 \text { : } \\
9 \text { males ( } 55.53 \pm 14.73) 1 \text { the } \\
\text { control group: 22: } 12 \text { males } \\
(54.85 \pm 13.40)\end{array}$ & $\begin{array}{l}\text { Regular rehabilitation } \\
\text { treatment + VRGs treatment; } \\
20 \text { minutes/time, } 5 \text { times/week, } \\
12 \text { weeks in total; } 1200 \text { min }\end{array}$ & Hospital & $\begin{array}{l}\text { The Biomaster } \\
\text { VR training } \\
\text { system } \\
\text { produced in } \\
\text { Guangzhou }\end{array}$ & $\begin{array}{l}\text { Picture matching, } \\
\text { skiing, football }\end{array}$ & (3) \\
\hline
\end{tabular}

Note: NSL: The male to female ratio is not mentioned; L:Gross Motor Function Classification System Level of Cerebral Palsy; GMFCS: Gross Motor Function Classification System; VRGs:

Virtual reality games; (1): Movement Assessment Battery for Children (M-ABC, the balance test); (2): Pediatric Balance Scale (PBS); (3): Berg Balance Scale (BBS); (4): Nintendo Wii Fit Balance Board Score; (5): Timed Up and Go (TUG); (6): Pediatric balance measurement (PBM). 


\subsection{Methodological Quality}

For the quality assessment of included studies, the agreement among assessors was $94.5 \%$. According to the PEDro scale, the methodological quality of all the experimental studies ranged from 5 to 6 . The higher the score, the lower the risk of bias (Table 2). Ten studies were deemed to have a moderate risk of bias. Since allocation concealment was not conducted in all the included studies, the quality of included studies decreased. Blinding was not frequently carried out in the studies (it was only conducted in one study [31]), so the score of blinding was deducted for most of the studies.

Table 2. Methodological quality assessment for the included studies.

\begin{tabular}{ccccccccccccc}
\hline Included Studies & A & B & C & D & E & F & G & H & I & J & K & Score \\
\hline Han et al. [39] (2010) & Yes & Yes & No & Yes & No & No & No & Yes & Not clear & Yes & No & $5 / 11$ \\
Sharanl et al. [32] (2012) & Yes & Yes & No & Yes & No & No & No & Yes & Not clear & Yes & No & $5 / 11$ \\
Alsaif and Alsenany. [33] (2015) & Yes & Yes & No & Yes & No & No & No & Yes & Not clear & Yes & No & $5 / 11$ \\
Atasavun et al. [31] (2016) & Yes & Yes & No & Yes & No & No & Yes & Yes & No & Yes & No & $6 / 11$ \\
Trakci et al. [14](2016) & Yes & Yes & No & Yes & No & No & No & Yes & Not clear & Yes & No & $5 / 11$ \\
Ren et al. [37] (2016) & Yes & Yes & No & Yes & No & No & No & Yes & No & Yes & No & $5 / 11$ \\
Rgen et al. [34](2016) & Yes & Yes & No & Yes & No & No & No & Yes & No & Yes & No & $5 / 11$ \\
Sajan et al. [35] (2017) & Yes & Yes & No & Yes & No & No & No & Yes & Yes & Yes & No & $5 / 11$ \\
Zhao et al. [36](2018) & Yes & Yes & No & Yes & No & No & No & Yes & No & Yes & No & $5 / 11$ \\
Hsieh et al. [30] (2018) & Yes & Yes & No & Yes & No & No & No & Yes & No & Yes & No & $5 / 11$ \\
Yang et al. [38](2019) & Yes & Yes & No & Yes & No & No & No & Yes & Not clear & Yes & No & $5 / 11$ \\
\hline
\end{tabular}

Note: A. eligibility criteria were specified; B. subjects were randomly allocated to groups; $\mathbf{C}$. allocation was concealed; D. the groups were similar at baseline regarding the most important outcome indicators; E. there was blinding of all subjects; F. there was blinding of all therapists; G. there was blinding of all assessors; H. measures of at least one key outcome were obtained from more than $85 \%$ of the subjects initially allocated to groups; I. all subjects for whom outcome measures were available received the treatment or, where this was not the case, data for at least one key outcome was analyzed by "intention to treat"; J. the results of between-group statistical comparisons were reported for at least one key outcome; K. the study provided both point measures and measures of variability for at least one key outcome.

\subsection{The Effect of VR Games on the Balance of Children with Cerebral Palsy}

3.4.1. The Effect of VR Games on the Balance of Children with Cerebral Palsy for VR Game Groups and Control Groups

This research includes 11 RCT studies with 14 RCT data points, with the mean effect size being 0.29 when all the studies were included (the random effects model), and the funnel plot did not show significant asymmetry (Figure 2) (Egger's regression intercept $=0.38, p=0.23$ ). Meta-analysis was performed on all RCT data to test the impact upon balance of children with $\mathrm{CP}$, which was measured by different tools, in VR game groups and control groups. The result showed that VR games had a significant effect on the balance of children with CP (small effect, no heterogeneity, Hedge's g $=0.29$, $p<0.05, I^{2}=0 \%$ ) (Figure 3).

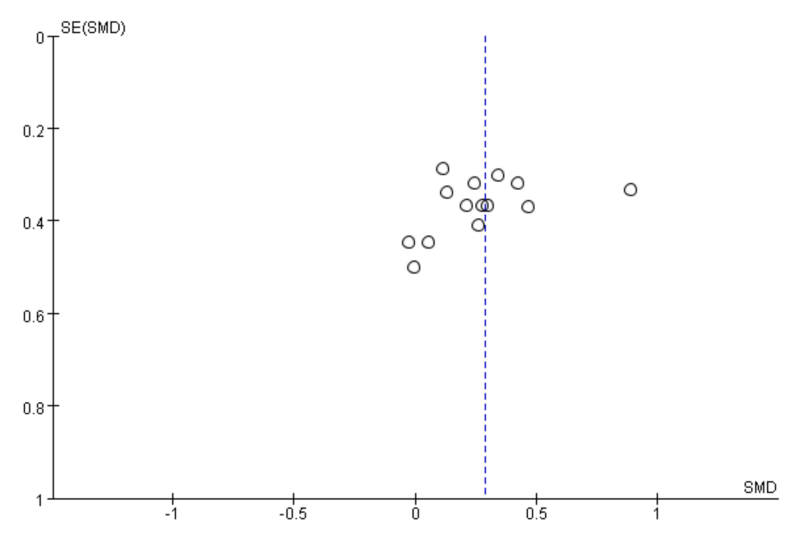

Figure 2. The funnel plot of the effect of VR games on the balance of children with CP. 


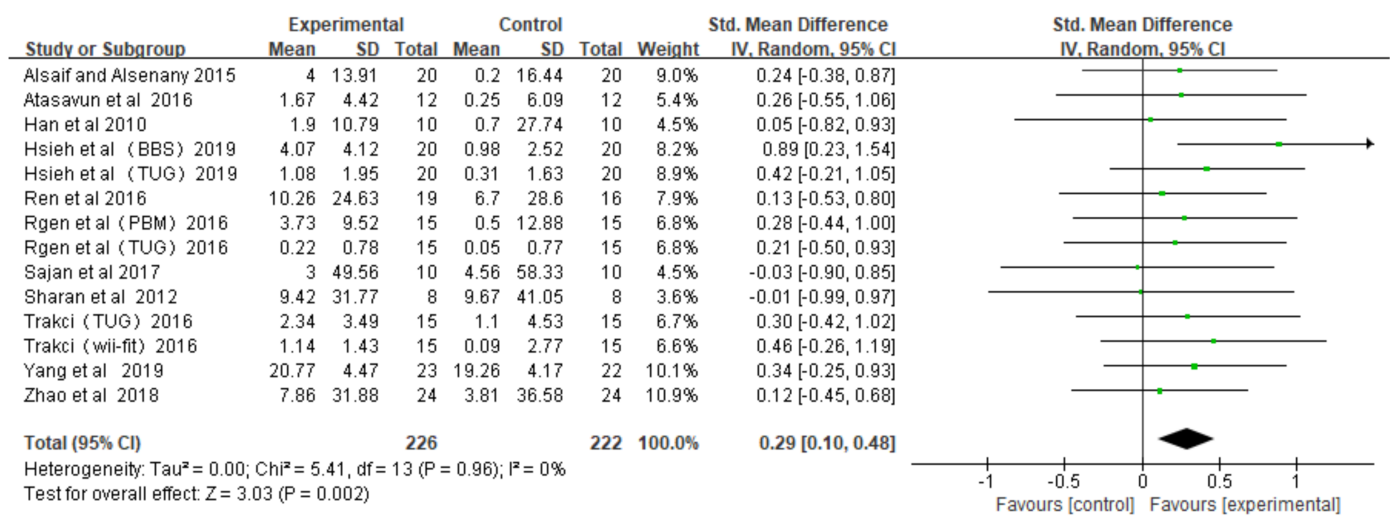

Figure 3. The effect of VR games on the balance of children with cerebral palsy.

\subsubsection{Regulatory Impact Analysis}

The results of subgroup analysis of VR game intervention in the balance of children with $\mathrm{CP}$ are shown in Table 3. It can be seen that because one study [32] did not report specific intervention times and frequencies that were not included in the subgroup analysis, the Session length $(p=0.70)$, intervention frequency every week $(p=0.96)$, Intervention cycle $(p=0.33)$ and the total time of intervention $(p=0.34)$ showed no significant influence.

Table 3. The regulatory impact analysis of VR game groups and control groups.

\begin{tabular}{|c|c|c|c|c|c|c|}
\hline Regulatory Impact & $\begin{array}{l}\text { Categorical Variables for } \\
\text { Sub-Group Analysis }\end{array}$ & PC & Hedge's g & $95 \% \mathrm{CI}$ & $I^{2}$ & $\begin{array}{c}\text { Between-Group } \\
\text { Difference } \\
p\end{array}$ \\
\hline \multirow{2}{*}{ Session length } & 15 to $40 \mathrm{~min}$; & 7 & 0.26 & -0.01 to 0.53 & $0 \%$ & \multirow{2}{*}{0.70} \\
\hline & $\geq 40 \mathrm{~min}$ & 6 & 0.34 & 0.07 to 0.60 & $0 \%$ & \\
\hline \multirow{2}{*}{$\begin{array}{l}\text { Intervention } \\
\text { frequency }\end{array}$} & 2 to 5 sessions/weekly; & 6 & 0.27 & -0.04 to 0.58 & $0 \%$ & \multirow[b]{2}{*}{0.96} \\
\hline & $\geq 5$ sessions/weekly & 7 & 0.32 & 0.07 to 0.56 & $0 \%$ & \\
\hline \multirow{2}{*}{ Intervention cycle } & 3 to 12 weeks & 4 & 0.15 & -0.19 to 0.50 & $0 \%$ & \multirow{2}{*}{0.33} \\
\hline & $\geq 12$ weeks & 9 & 0.36 & 0.13 to 0.59 & $0 \%$ & \\
\hline \multirow{2}{*}{$\begin{array}{l}\text { Total time of } \\
\text { intervention }\end{array}$} & 480 to $1000 \mathrm{~min}$; & 8 & 0.21 & -0.04 to 0.47 & $0 \%$ & \multirow{2}{*}{0.34} \\
\hline & $\geq 1000 \mathrm{~min}$ & 5 & 0.40 & 0.12 to 0.68 & $0 \%$ & \\
\hline
\end{tabular}

Note: $\mathrm{PC}=$ pair-comparison.

\section{Discussion}

The results of the present meta-analysis of RCTs evaluating the impact of VR games upon the balance of children with CP showed that VR games had a positive effect on the balance of children with CP compared with traditional rehabilitation methods (Hedge's $g=0.29 ; 95 \%$ CI $0.10-0.48, p<0.05$ ). However, The study found the session length, intervention frequency every week, Intervention cycle and the total time of intervention showed no significant influence. The reason may be the insufficient number of existing studies, the small number of children with cerebral palsy participating in the experiment and other reasons. The development of various VR games provides new methods of, and approaches to, the treatment of children with CP for clinical staff, and VR games can keep children engaged and doing repetitive rehabilitation exercises. In contrast, traditional dyskinesia treatments require various games and facilities, such as bowling balls, obstacles, and baskets of different heights, and a relatively large space for treatment. Apart from that, traditional rehabilitation treatments also need (a) seasoned therapist(s) to communicate with and encourage children, so as to ensure smooth treatment by increasing children's excitement and interest [12,40]. Compared with traditional schemes, VR game interventions can be performed in a smaller room, and the interaction of VR game device 
provides a challenging, encouraging and safe environment, so children with $\mathrm{CP}$ who are often unwilling to receive traditional therapy may choose VR game treatment $[12,40]$.

This research holds that the improvement of visual perception, muscle strength, and motor skills on the hemiplegic side by VR games plays the most important role in the enhancement of the balance of children with CP. For example, Bilde et al. [3] found that muscle strength and visual perceptions of children with CP were significantly improved after a VR game intervention. Snider et al. [41] also showed that VR games could improve the visual perception and movement stability of children with $\mathrm{CP}$. Cho et al. [42] found that VR games increased the lower limb strength of children with $\mathrm{CP}$, thereby raising the postural control of these children, enhancing their body symmetry and balance ability.

Chiu et al. [43] noted through the parents' reports in their study that children's arms on the hemiplegic side developed new movements (for instance, their forearms could rotate outward). Surprisingly, Rgen et al. [34] found that compared with the children undergoing traditional rehabilitation treatments, the children with CP playing VR games remarkably managed to jump more times with their leg on the hemiplegic side, especially in ski jumping and racing games. The improvement of motor skills on the hemiplegic side can effectively reduce the compensation, keeping body muscles working at the same time and helping with the maintenance of balance.

The advantage of this research lies in the relatively comprehensive study results retrieved, and only RCTs regarding the balance of children with CP. Further, standardized quality assessment tools were adopted, and the heterogeneity of included studies was evaluated. Moreover, the funnel plot and Egger's test were used to assess publication bias.

Nevertheless, there are limitations in the evaluated studies mainly due to methodological issues. Firstly, there were only 14 RCT data points in our meta-analysis, so the sample size is relatively small, and the included studies may not be as comprehensive as they could be. More well-designed trials with large sample size are needed in future. Some non-peer reviewed papers were not included in the research, so publication bias may exist. Secondly, included studies concerned different VR game intervention schemes and such differences may induce study heterogeneity. The subjects included in this research also varied, though they were all children with $\mathrm{CP}$; the effect of intervention may be different owing to different GMFCS levels. Thirdly, included studies were limited by insufficient description of blinding and randomized control. Experimental procedures of future studies should be transparently reported. In addition, the most important limitation of this research is that the included studies used VR in combination with other rehabilitation programs, so it may be difficult to conclude that improvement was entirely due to VR game intervention. In addition, as the intervention schemes in included studies varied greatly, it is difficult to give specific suggestions on the intervention time and frequency. These issues should be addressed in future studies.

\section{Conclusions}

In conclusion, existing studies show that VR games play a positive role in the improvement of the balance of children with CP. However, the limitations in the current methodology may affect the results of this meta-analysis. More rigorous and reliable RCTs are needed in the future to more accurately determine the improvement effect of VR games on the balance of children with $\mathrm{CP}$ as well as the long-term impact of the games upon the balance development of children with $\mathrm{CP}$.

Author Contributions: J.W. and Z.R. contributed to the conception and design of the review. J.W. applied the search strategy. J.W. and Z.R. applied the selection criteria. J.W. and Z.R. completed assessment of risk of bias. P.D.L. analyzed and interpreted the data. J.W. wrote this manuscript. P.D.L. edited this manuscript. Z.R. is responsible for the overall project.

Funding: This research was funded by [Humanities and Social Science, ShenZhen University, Young Teacher Award] grant number [17QNFC59], [Philosophy and Social Sciences in Guangdong Province] grant number [GD16CTY03] and [Key project of shenzhen education science in 2018] grant number [zdfz18008].

Acknowledgments: The leading author would like to thank his family members (parents) for their consistent support. 
Conflicts of Interest: The authors declare no conflict of interest.

\section{References}

1. Chen, X.J.; Li, S. The Definition, Typology and Diagnostic Criteria of Children's Cerebral Palsy. Chin. J. Phys. Med. Rehabil. 2007, 5, 309.

2. Li, P.; Li, Z.; Deng, A. Research Progress of Family Support in Children with Cerebral Palsy. Chin. J. Nurs. 2013, 4, 365-367.

3. Bilde, P.E.; Kliim-Due, M.; Rasmussen, B.; Petersen, L.Z.; Petersen, T.H.; Nielsen, J.B. Individualized, home-based interactive training of cerebral palsy children delivered through the Internet. BMC Neurol. 2011, 11, 32. [CrossRef] [PubMed]

4. Gormley, M.J. Treatment of neuromuscular and musculoskeletal problems in cerebral palsy. Pediatr. Rehabil. 2001, 4, 5-16. [PubMed]

5. Nashner, L.M.; Shumway-Cook, A.; Marin, O. Stance posture control in select groups of children with cerebral palsy: Deficits in sensory organization and muscular coordination. Exp. Brain Res. 1983, 49, 393-409. [CrossRef] [PubMed]

6. Chen, C.L.; Shen, I.H.; Chen, C.Y.; Wu, C.Y.; Liu, W.Y.; Chung, C.Y. Validity, responsiveness, minimal detectable change, and minimal clinically important change of Pediatric Balance Scale in children with cerebral palsy. Res. Dev. Disabil. 2013, 34, 916-922. [CrossRef]

7. Zou, L.; Loprinzi, P.D.; Yu, J.J.; Li, C.; Yeung, A.S.; Kong, Z.; Chiou, S.Y.; Xiao, T. Superior effects of modified Chen-style Tai Chi versus 24-Tai Chi on cognitive function, fitness, and balance performance in adults over 55. Brain Sci. 2019, 9, 102. [CrossRef]

8. Zhou, S.; Zhang, Y.; Kong, Z.; Loprinzi, P.D.; Hu, Y.; Ye, J.; Liu, S.; Yu, J.J.; Zou, L. The Effects of Tai Chi on Markers of Atherosclerosis, Lower-limb Physical Function, and Cognitive Ability in Adults Aged Over 60: A Randomized Controlled Trial. Int. J. Environ. Res. Public Health 2019, 16, 753. [CrossRef]

9. Xu, K.S.; Yan, T.B.; Mai, J.N. A Comparative Study on the Treatment for Spasm of Plantar Flexors of Children with Cerebral Palsy with Botulinum Toxin Guided by Different Localization Techniques. Chin. J. Phys. Med. Rehabil. 2006, 9, 607-610.

10. Kong, Z.W.; Sze, T.M.; Yu, J.; Xiao, T.; Yeung, A.; Li, C.X.; Zhang, H.; Zou, L. Tai Chi as an Alternative Exercise to Improve Physical Fitness for Children and Adolescents with Intellectual Disability. Int. J. Environ. Res. Public Health 2019, 16, 1152. [CrossRef]

11. Qi, L.; Aihua, Z. The Players' Experiencing Space Composition and Emotional Characteristics in 3D Active Video Games. Art Educ. 2012, 12, 191.

12. Ravim, D.K.; Kumar, N.; Singhi, P. Effectiveness of virtual reality rehabilitation for children and adolescents with cerebral palsy: An updated evidence-based systematic review. Physiotherapy 2017, 103, $245-258$. [CrossRef] [PubMed]

13. You, S.H.; Jang, S.H.; Kim, Y.H.; Hallett, M.; Ahn, S.H.; Kwon, Y.H.; Kim, J.H.; Lee, M.Y. Virtual reality-induced cortical reorganization and associated locomotor recovery in chronic stroke: An experimenter-blind randomized study. Stroke 2005, 36, 1166-1171. [CrossRef] [PubMed]

14. Tarakci, D.; Ersoz, H.B.; Tarakci, E.; Razak, O.A. Effects of Nintendo Wii-Fit((R)) video games on balance in children with mild cerebral palsy. Pediatr. Int. 2016, 58, 1042-1050. [CrossRef]

15. Chen, L.; Lo, W.L.; Mao, Y.R.; Ding, M.H.; Lin, Q.; Li, H.; Zhao, J.L.; Xu, Z.Q.; Bian, R.H.; Huang, D.F. Effect of Virtual Reality on Postural and Balance Control in Patients with Stroke: A Systematic Literature Review. BioMed Res. Int. 2016. [CrossRef]

16. Qi, L.; Zhang, A. Players' experience space composition and emotional characteristics in 3D somatosensory games. Prog. Brain Res. 2012, 12, 191.

17. Ashkenazi, T.; Laufer, Y.; Orian, D.; Weiss, P.L. Effect of training children with Developmental Coordination Disorders in a virtual environment compared with a conventional environment. In Proceedings of the International Conference on Virtual Rehabilitation, Philadelphia, PA, USA, 26-29 August 2013.

18. Chen, Y.P.; Lee, S.Y.; Howard, A.M. Effect of virtual reality on upper extremity function in children with cerebral palsy: A meta-analysis. Pediatr. Phys. Ther. 2014, 26, 289-300. [CrossRef]

19. Pin, T.W. Effectiveness of interactive computer play on balance and postural control for children with cerebral palsy: A systematic review. Gait Posture 2019, 73, 126-139. [CrossRef] 
20. Loprinzi, P.D.; Ponce, P.; Zou, L.; Li, H. The Counteracting Effects of Exercise on High-Fat Diet-Induced Memory Impairment: A Systematic Review. Brain Sci. 2019, 9, 145. [CrossRef]

21. Zou, L.; Loprinzi, P.D.; Yeung, A.S.; Zeng, N.; Huang, T. The Beneficial Effects of Mind-Body Exercises for People with Mild Cognitive Impairment: A Systematic Review with Meta-analysis. Arch. Phys. Med. Rehabil. 2019, 100, 1556-1573. [CrossRef]

22. Li, H.J.; He, L.Y.; Liu, Z.S.; Sun, Y.N.; Yan, S.Y.; Liu, J.; Zhao, Y.; Liu, B.Y. On-site quality control of acupuncture randomized controlled trial: Design of content and checklist of quality control based on PICOST. Zhongguo Zhen Jiu 2014, 34, 183-185. [PubMed]

23. Zou, L.; Sasaki, J.E.; Wei, G.X.; Huang, T.; Yeung, A.S.; Neto, O.B.; Chen, K.W.; Hui, S.S. Effects of Mind(-)Body Exercises (Tai Chi/Yoga) on Heart Rate Variability Parameters and Perceived Stress: A Systematic Review with Meta-Analysis of Randomized Controlled Trials. J. Clin. Med. 2018, 7, 404. [CrossRef] [PubMed]

24. Zou, L.; Sasaki, J.E.; Zeng, N.; Wang, C.; Sun, L. A Systematic Review with Meta-Analysis of Mindful Exercises on Rehabilitative Outcomes among Poststroke Patients. Arch. Phys. Med. Rehabil. 2018, 99, 2355-2364. [CrossRef] [PubMed]

25. Zhang, Y.; Loprinzi, P.D.; Yang, L.; Liu, J.; Liu, S.; Zou, L. The Beneficial Effects of Traditional Chinese Exercises for Adults with Low Back Pain: A Meta-Analysis of Randomized Controlled Trials. Medicina 2019, 55, 118. [CrossRef]

26. Zou, L.; Zhang, Y.; Yang, L.; Loprinzi, P.D.; Yeung, A.S.; Kong, J.; Chen, K.W.; Song, W.; Xiao, T.; Li, H. Are Mindful Exercises Safe and Beneficial for Treating Chronic Lower Back Pain? A Systematic Review and Meta-Analysis of Randomized Controlled Trials. J. Clin. Med. 2019, 8, 628. [CrossRef]

27. Zou, L.; Han, J.; Li, C.; Yeung, A.S.; Hui, S.S.; Tsang, W.; Ren, Z.; Wang, L. Effects of Tai Chi on Lower Limb Proprioception in Adults Aged Over 55: A Systematic Review and Meta-Analysis. Arch. Phys. Med. Rehabil. 2019, 100, 1102-1113. [CrossRef]

28. Zhang, Y.; Li, C.; Zou, L.; Liu, X.; Song, W. The Effects of Mind-Body Exercise on Cognitive Performance in Elderly: A Systematic Review and Meta-Analysis. Int. J. Environ. Res. Public Health 2018, 15, 2791. [CrossRef]

29. Liu, S.; Wang, L.; Li, R.; Wei, G.; Ren, R.; Zou, L. Mind-Body (Baduanjin) Exercise Prescription for Chronic Obstructive Pulmonary Disease: A Systematic Review with Meta-Analysis. Int. J. Environ. Res. Public Health 2018, 15, 1830. [CrossRef]

30. Hsieh, H.C. Effects of a Gaming Platform on Balance Training for Children with Cerebral Palsy. Pediatr. Phys. Ther. 2018, 30, 303-308. [CrossRef]

31. Atasavun, U.S.; Baltaci, G. Effects of Nintendo Wii ${ }^{\mathrm{TM}}$ Training on Occupational Performance, Balance, and Daily Living Activities in Children with Spastic Hemiplegic Cerebral Palsy: A Single-Blind and Randomized Trial. Games Health J. 2016, 5, 311-317. [CrossRef]

32. Sharan, D.; Ajeesh, P.S.; Rameshkumar, R.; Mathankumar, M.; Paulina, R.J.; Manjula, M. Virtual reality-based therapy for post-operative rehabilitation of children with cerebral palsy. Work 2012, 41 (Suppl. 1), 3612-3615.

33. AlSaif, A.A.; Alsenany, S. Effects of interactive games on motor performance in children with spastic cerebral palsy. J. Phys. Ther. Sci. 2015, 27, 2001-2003. [CrossRef] [PubMed]

34. Rgen, M.; Akbayrak, T.; Gunel, M.; Cankaya, O.; Guchan, Z.; Turkyilmaz, E. Investigation of the effects of the Nintendo ${ }^{\circledR}$ Wii-Fit training on balance and advanced motor performance in children with spastic hemiplegic cerebral palsy: A Randomized Controlled Trial. Int. J. Ther. Rehabil. Res. 2016, 5. [CrossRef]

35. Sajan, J.E.; John, J.A.; Grace, P.; Sabu, S.S.; Tharion, G. Wii-based interactive video games as a supplement to conventional therapy for rehabilitation of children with cerebral palsy: A pilot, randomized controlled trial. Dev. Neurorehabil. 2017, 20, 361-367. [CrossRef] [PubMed]

36. Zhao, X.k.; Zhang, Y.; Du, S. Influence of Movement Observation Training Fulfilled by Active Video Games on Motor Function of Children with Spastic Cerebral Palsy. Chin. J. Phys. Med. Rehabil. 2018, 12, 916-918.

37. Ren, K.; Gong, X.M.; Zhang, R. Influence of Virtual Reality Training on Gross Motor Skills and Walking Pace of Children with Spastic Cerebral Palsy. Matern. Child Health Care China 2019, 4, 291-292.

38. Yang, M.X.; Zhang, W.T.; Fu, J.M. Impact of Virtual Reality Training Techniques on the Balance of Children with Spastic Cerebral Pals. Chin. J. Phys. Med. Rehabil. 2019, 4, 291-293.

39. Han, J.; Ko, J. Evaluation of Balance and Activities of Daily Living in Children with Spastic Cerebral Palsy using Virtual Reality Program with Electronic Games. J. Korea Contents Assoc. 2010, 10, 480-488. [CrossRef]

40. Harris, K.; Reid, D. The influence of virtual reality play on children's motivation. Can. J. Occup. Ther. 2005, 72, 21-29. [CrossRef] 
41. Snider, L.; Majnemer, A.; Darsaklis, V. Virtual reality as a therapeutic modality for children with cerebral palsy. Dev. Neurorehabil. 2010, 13, 120-128. [CrossRef]

42. Cho, C.; Hwang, W.; Hwang, S.; Chung, Y. Treadmill Training with Virtual Reality Improves Gait, Balance, and Muscle Strength in Children with Cerebral Palsy. Tohoku J. Exp. Med. 2016, 238, 213-218. [CrossRef]

43. Chiu, H.C.; Ada, L.; Lee, H.M. Upper limb training using Wii Sports Resort for children with hemiplegic cerebral palsy: A randomized, single-blind trial. Clin. Rehabil. 2014, 28, 1015-1024. [CrossRef]

(C) 2019 by the authors. Licensee MDPI, Basel, Switzerland. This article is an open access article distributed under the terms and conditions of the Creative Commons Attribution (CC BY) license (http://creativecommons.org/licenses/by/4.0/). 